\title{
Research on flux decline in nanofiltration of lactic acid solutions with ZRIV/PAA membranes application
}

\author{
Ewa Połom \\ West Pomeranian University of Technology, Szczecin, Faculty of Chemical Technology and Engineering, Chemical \\ Engineering and Environmental Protection Institute, al. Piastów 42, 71-065 Szczecin, Poland \\ "Corresponding author: e-mail: ewa.polom@zut.edu.pl
}

\begin{abstract}
The efficiency of lactic acid solutions nanofiltration with dynamically formed zirconium (IV) hydrous oxide polyacrylate (ZrIV/PAA) membranes application were considered in this paper. The results of investigations on flux decline in nanofiltration of lactic acid solutions under conditions resulting in low and high lactic acid rejection are reported. In the long term experimental research on pressure driven membrane processes the main reason of permeate flux reduction is an accumulation of concentration polarization and fouling effects. The experimental permeate flux versus time curves were analyzed in the frame of resistance-in-series model with the aim to develop the characteristic fouling and concentration polarization resistances. The analysis of experimental data and results of calculations showed that both: concentration polarization and fouling phenomena in investigated system depend on hydrodynamic conditions and properties of filtered solutions and (ZrIV/PAA) membrane.
\end{abstract}

Keywords: nanofiltration, dynamically formed membranes, lactic acid, flux decline, resistance in series model.

\section{INTRODUCTION}

Lactic acid is a highly valuated product that is widely used in food processing and pharmaceutical industry but its primary application is based for biodegradable polymers production. Lactic acid can be obtained by two different ways: chemical synthesis from oil- based non-renewable resources or biotechnical fermentative processes starting from renewable resources ${ }^{1}$.

In recent years, the amount of lactic acid produced by biotechnological methods has increased significantly. In dairy industry whey is considered as a main waste, on the other hand it could be source of valuable products such as: lactose, proteins or raw material for lactic acid production in a fermentation process. One of the possibilities to utilize whey is the fermentation of lactose made by lactic acid bacteria to lactic acid ${ }^{1-5}$. The membrane approach for lactic acid production from waste lactose is presented in Figure 1.

The distinctive feature of bioprocess is the necessity separating precisely the desired products from multicom-

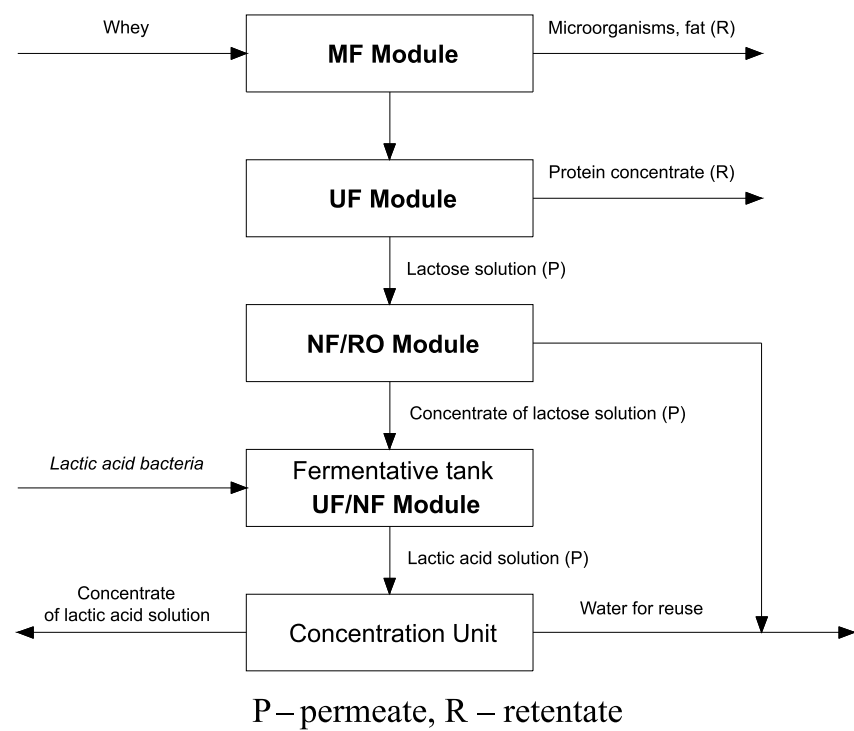

Figure 1. The conception of lactic acid production from whey with pressure membrane processes employment ${ }^{5}$ ponent and usually much diluted systems. The lactic acid, as the final product and the inhibitor of fermentation process, has to be separated from fermentation broth and in the next step purified and concentrated. The fermentation process can be performed in batch or in continuous mode. The continuous process is characterized by higher productivity than the batch fermentation. The lactic acid obtained by fermentation process has to be separated from fermentation broth, purified and concentrated to the commercial level. There is applied neutralization with base followed by filtration, concentration and acidification, in the conventional process of lactic acid producing. In practice, the most popular are hybrid technologies employing membrane processes as an alternative to conventional techniques. During the continuous fermentation bioreactors coupled with membrane units permit for continuous removal of lactic acid from the fermentation broth and also recovery of substrate and bacteria. The membrane approach for the final product concentration to the commercial level includes reverse osmosis or nanofiltration (NF) processes.

Nowadays, membrane separation processes are becoming an important tool for separation and concentration of wide range of materials and its applications can be found in food and chemical industries as well. One of the major limitation to the practical application of membranes is permeate flux reduction, defined in literature as concentration polarization and fouling phenomenon ${ }^{7-12}$. Many different methods, such as: pre-treatment of filtered solution or determination of the optimal operational parameters values, are used to minimise flux decline effects $^{7,11}$. On the other hand the membrane processes are regarded as environmental friendly techniques, which allow to save energy and substrates. Dynamically formed membranes are regarded as the most interesting separation medium in this area $\mathrm{a}^{2-4}$. These kinds of membranes can work in conditions resulting in low as well as in high solute rejection. Hence, they can be used for concentration and purification processes like lactic acid recovery from waste lactose obtained from whey. 
The dynamically formed membranes are special kind of inorganic membranes. They consist of a porous support and one or more gel layers. Because both the support and gel layer are of inorganic origin, those membranes are also called inorganic ones. The porous support is made out of powders, which are sintered in order to obtain proper structure. The gel layers are formed on the porous supports during the filtration of solutions containing membrane forming substances under appropriate cross-flow and pressure conditions.

The dynamically formed membranes have some interesting from practical point of view, advantages: high mechanical and chemical resistance, long life time, high thermal stability, possibility of in situ membrane replacement and high permeability corresponding to high rejection and only few disadvantages: relatively high construction cost and considerable weigh as well as low rate of compaction of membrane modules $2,4,5,14,15$.

The optimisation of nanofiltration (NF) efficiency is first of all bound by the proper choice of operational parameters. In the previous papers the aim of the research was the attainment of range of optimum conditions for nanofiltration resulting in low and high lactic acid rejections with high pressure zirconium (IV) hydrous oxide polyacrylate dynamically formed membranes, $\mathrm{Zr}$ (IV)/PAA application $^{\mathbf{4}, \mathbf{1 3}}$. For this purpose the effect of operating parameters such as cross-flow velocity, transmembrane pressure, $\mathrm{pH}$ and lactic acid concentration in the feed solutions on lactic acid rejection was investigated using statistical $2^{4}$-factorial design.

This paper focuses on the description of flux decline in nanofiltration for operating parameters providing low and high lactic acid rejection with use of resistance-in-series model.

\section{EXPERIMENTAL}

\section{Zr(IV)/PAA membrane properties}

High-pressure $\mathrm{Zr}(\mathrm{IV})$ /PAA membranes were used in research on nanofiltration process of lactic acid model solutions. They were formed on a permanent titanium dioxide microfiltration membrane support with internal diameter, $0.016 \mathrm{~m}$ and area, $0.029 \mathrm{~m}^{2}$, produced by $\mathrm{Du}$ Pont Separation Systems (USA), in a two step dynamic process $^{2,4,5,14,15}$. Replacement of $\mathrm{Zr}(\mathrm{IV}) / \mathrm{PAA}$ membrane is possible by three-step rinsing process.

Morphological characteristic of $\mathrm{Zr}$ (IV)/PAA membrane $\mathrm{e}^{\mathbf{1 4}, \mathbf{1 5}}$ is presented in Table 1 .

\section{Cross-flow filtration unit}

The research on nanofiltration process of lactic acid solutions was performed with use of high pressure membrane installation equipped with tubular module and zirconium (IV) hydrous oxide dynamically formed membrane. The side valve gave possibility of velocity regulation at constant pressure. The scheme of experimental set up is presented in Figure 2.

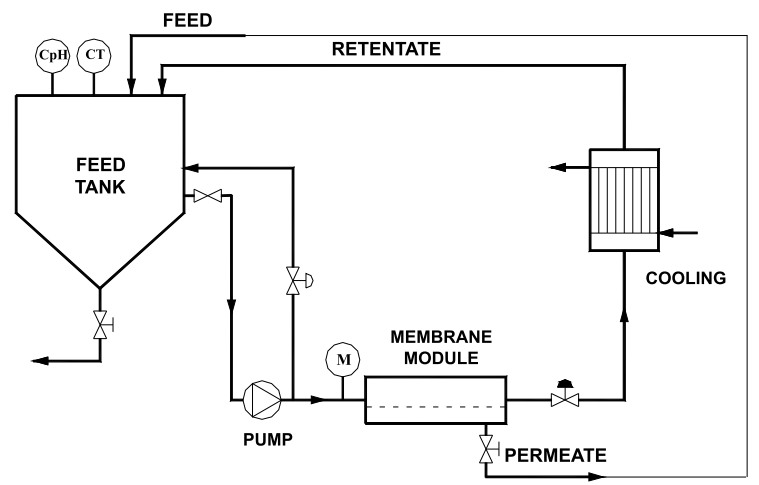

$\mathrm{CpH}-\mathrm{pH}$, meter, $\mathrm{CT}-$ temperature meter, $\mathrm{M}$ - pressure control

Figure 2. Scheme of experimental set-up

The temperature was regulated with a heat exchanger on the retentate circulation loop and was maintained at the level of $40^{\circ} \mathrm{C}$ during the time of measurements.

During the experiments lactic acid solutions were pumped from the feed tank to the one pipe membrane module in a cross - flow filtration mode and then both permeate and retentate were recirculated back to the feed tank. After each measurement fouled membrane was rinsed with deionised water in 4 hours periods at open permeate outlet valve. This way of research set-up gave possibility to estimate an impact of operating parameters on permeate flux reduction.

Concentration of lactic acid was measured by HPLC method with 440 Absorbance Detector supplied by Waters Associates. Samples of retentate and permeate were collected for the analysis in a 30 minutes periods during first 3 hours and then each hour of experimental cycle.

\section{Operating conditions of nanofiltration experiments}

Nanofiltration experiments were performed at constant temperature of $40^{\circ} \mathrm{C}$ for operating parameters resulting in low and high lactic acid rejection. The operating parameters for analysis of concentration polarization and fouling phenomena evaluated earlier using statistical design method are presented in Table $2^{\mathbf{4}, \mathbf{1 3}}$.

Table 1. Characteristic of dynamically formed membranes used in the research

\begin{tabular}{|c|c|c|c|}
\hline Membrane type & Support & Gel layer & Nomenclature \\
\hline $\mathrm{Ti}(\mathrm{IV})$ & Stainless steel (SS) & $\mathrm{TiO}_{2}$ (permanent) & MF \\
\hline $\mathrm{Zr}(\mathrm{IV})$ & $\mathrm{SS} / \mathrm{TiO}_{2}$ & $\mathrm{ZrO}(\mathrm{OH})_{2}$ & UF \\
\hline $\mathrm{Ti}(\mathrm{IV}) / \mathrm{Zr}(\mathrm{IV}) / \mathrm{PAA}$ & $\mathrm{SS} / \mathrm{TiO} 2 / \mathrm{ZrO}(\mathrm{OH})_{2}$ & $\begin{array}{c}\text { polyacrylic acid } \\
\text { PAA }\end{array}$ & NF \\
\hline
\end{tabular}

Table 2. Values of operating parameters chosen for flux decline analysis ${ }^{4,13}$

\begin{tabular}{|c|c|c|c|c|}
\hline Lactic acid rejection & \multicolumn{4}{|c|}{ Parameters } \\
\hline$R_{\min }$ & $\mathrm{u}, \mathrm{m} / \mathrm{s}$ & $\Delta \mathrm{p}, \mathrm{MPa}$ & $\mathrm{pH}$ & $\mathrm{C}_{\mathrm{LA}}, \mathrm{mol} / \mathrm{dm}^{3}$ \\
\hline 0.02 & 2.6 & 1.4 & 4.0 & 0.02 \\
\hline 0.09 & 1.0 & 1.4 & 4.0 & 1.00 \\
\hline 0.82 & 1.0 & 5.5 & 8.0 & 0.02 \\
\hline 0.58 & 2.6 & 5.5 & 8.0 & 1.00 \\
\hline
\end{tabular}


The investigated nanofiltration system provides low lactic acid rejection for both low $\left(c_{L A}=0.02 \mathrm{~mol} / \mathrm{dm}^{3}\right)$ and high $\left(c_{L A}=1.0 \mathrm{~mol} / \mathrm{dm}^{3}\right)$ lactic acid concentration in the feed solution at different velocity values $2.6 \mathrm{~m} / \mathrm{s}$ and $1.0 \mathrm{~m} / \mathrm{s}$. The high lactic acid rejection value have been obtained for lactic acid concentration increased from 0.02 to $1.0 \mathrm{~mol} / \mathrm{dm}^{3}$ at $\mathrm{pH}=8.0$ and cross-flow velocity decreased from $2.6 \mathrm{~m} / \mathrm{s}$ to $1.0 \mathrm{~m} / \mathrm{s}$ at transmembrane pressure $5.5 \mathrm{MPa}$.

\section{RESULTS AND DISCUSSION}

\section{Flux decline analysis}

The measurements of deionised water flux through clean membrane $\left(\mathrm{J}_{\mathrm{v}(\mathrm{dw})}\right.$ from Table 3$)$ were performed in four series, each of them last for eight hours. The experimental results of lactic acid solutions NF and NF of deionised water after each series are presented in Figures 3-6.

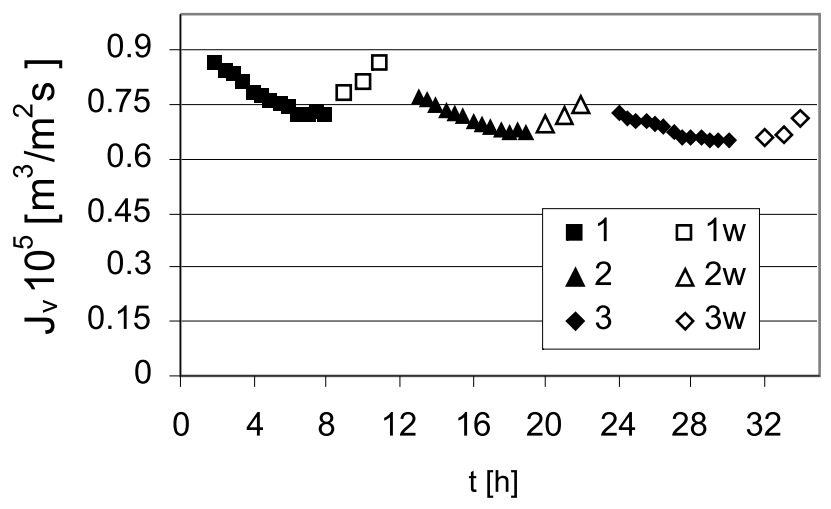

Figure 3. Permeate flux decline versus time for operating parameters providing high lactic acid rejection, $\mathrm{r}=$ 0.82 (Table 2); series 1, 2, 3 - nanofiltration of lactic acid solutions; series $1 \mathrm{w}, 2 \mathrm{w}, 3 \mathrm{w}-$ nanofiltration of water; concentration of lactic acid $c_{\mathrm{LA}}=0.02 \mathrm{~mol} / \mathrm{dm}^{3}$, $\mathrm{pH}=8.0$, transmembrane pressure $\Delta \mathrm{p}=5.5, \mathrm{MPa}$, cross flow velocity $\mathrm{u}=1.0, \mathrm{~m} / \mathrm{s}$

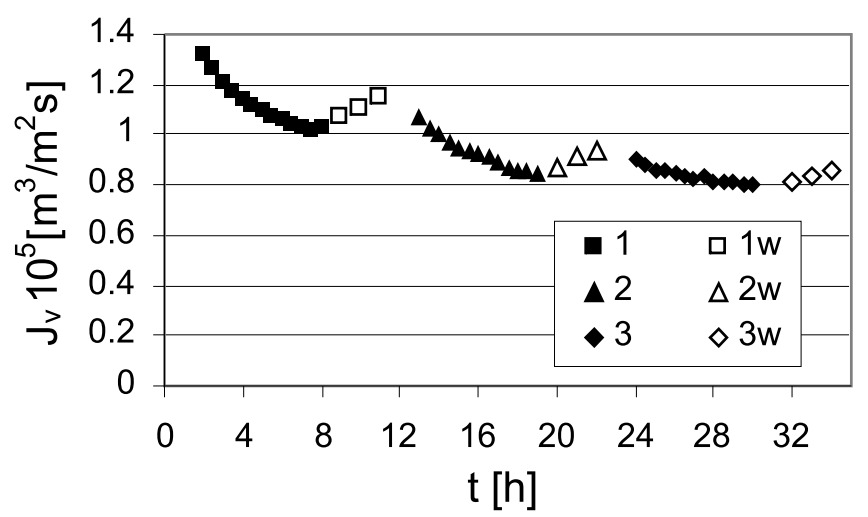

Figure 4. Permeate flux decline versus time for operating parameters providing high lactic acid rejection, $\mathrm{r}=0.58$ (Table 2); series 1, 2, 3 - nanofiltration of lactic acid solutions; series $1 \mathrm{w}, 2 \mathrm{w}, 3 \mathrm{w}-$ nanofiltrattion of water; concentration of lactic acid $\mathrm{c}_{\mathrm{LA}}=1.0 \mathrm{~mol} / \mathrm{dm}^{3}, \mathrm{pH}=8.0$, transmembrane pressure $\Delta \mathrm{p}=5.5, \mathrm{MPa}$, cross flow velocity $\mathrm{u}=2.6, \mathrm{~m} / \mathrm{s}$

The analysis of experimental results shows that hydrodynamic conditions and properties of filtered solutions were crucial to the $\mathrm{Zr}(\mathrm{IV}) / \mathrm{PAA}$ membrane efficiency.

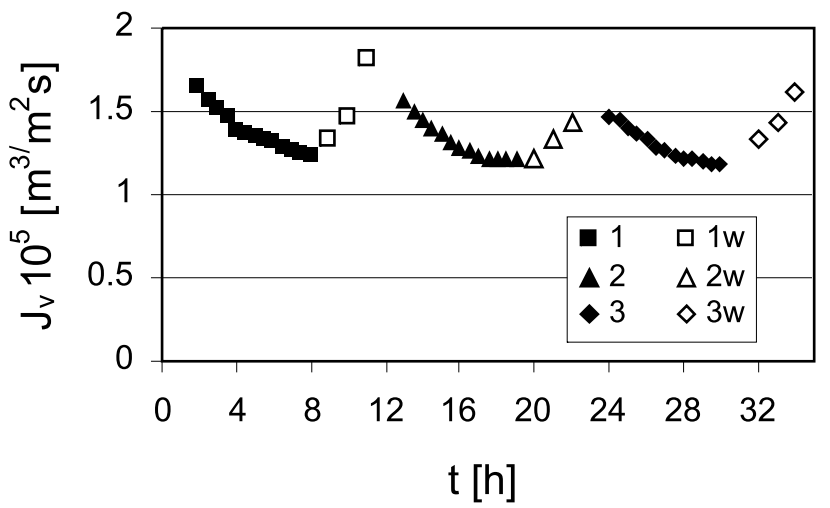

Figure 5. Permeate flux decline versus time for operating parameters providing low lactic acid rejection, $\mathrm{r}=0.02$ (Table 2); series 1, 2, 3 - nanofiltration of lactic acid solutions; series 1w, 2w, 3w-nanofiltration of deionised water; concentration of lactic acid $c_{\mathrm{LA}}=0.02 \mathrm{~mol} / \mathrm{dm}^{3}$, $\mathrm{pH}=4.0$, transmembrane pressure $\Delta \mathrm{p}=1.4, \mathrm{MPa}$, cross flow velocity $\mathrm{u}=2.6, \mathrm{~m} / \mathrm{s}$

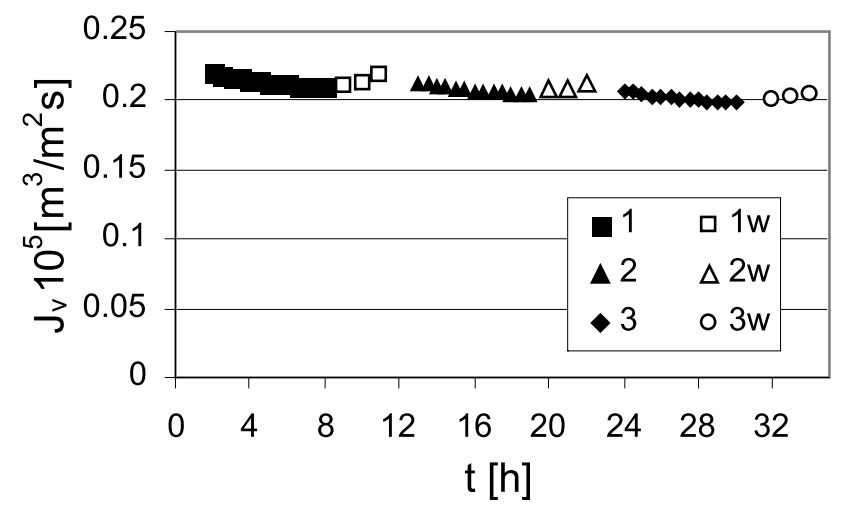

Figure 6. Permeate flux decline versus time for operating parameters providing low lactic acid rejection, $r=0.09$ (Table 2); series 1, 2, 3- nanofiltration of lactic acid solutions; series $1 \mathrm{w}, 2 \mathrm{w}, 3 \mathrm{w}$ - nanofiltration of deionised water; concentration of lactic acid $\mathrm{c}_{\mathrm{LA}}=1.0 \mathrm{~mol} / \mathrm{dm}^{3}$, $\mathrm{pH}=4.0$, transmembrane pressure $\Delta \mathrm{p}=1.4, \mathrm{MPa}$, cross flow velocity $\mathrm{u}=1.0, \mathrm{~m} / \mathrm{s}$

Characteristic of flux decline during the experiments of nanofiltration of lactic acid solutions changed due to the operating parameters.

High lactic acid concentration in feed solution generate increase of mass transfer resistance and reduce of permeate flux at high (Fig. 4) and low transmembrane pressure (Fig. 6).

The strong impact on decreasing efficiency of lactic acid nanofiltration process is observed for high value of transmembrane pressure, $\Delta \mathrm{p}=5.5 \mathrm{MPa}, \mathrm{pH}=8.0$ and lactic acid concentration, $\mathrm{c}_{\mathrm{LA}}=1.0 \mathrm{~mol} / \mathrm{dm}^{3}$ (Fig. 4). Configured in such conditions operational parameters of experiment causes problems with effectiveness of water cleaning in short 3 hour terms.

Effect of $\mathrm{pH}$ on both selectivity as well as the effectiveness of nanofiltration process is connected with characteristic behaviour of $\mathrm{Zr}(\mathrm{IV}) / \mathrm{PAA}$ membranes is that electrolyte rejection increases with increasing of $\mathrm{pH}$ in the feed solutions due to increase of membrane charge (Fig. 3) , $^{5}$.

For presented results impact of both transmembrane pressure and crossflow velocity could not be ignored. In regard to both increasing cross-flow velocity (Fig. 6) an low trans membrane pressure (Fig. 6) negative con- 
sequences of concentration polarization and fouling are reduced.

\section{Fouling resistances}

The experimental data concerning flux decline versus time allow to estimate the main mass transport resistances caused by fouling phenomena: reversible fouling resistance $R_{r f}$ and irreversible fouling resistance $R_{i f}$.

According to the resistance-in-series model ${ }^{8-12}$ permeate fluxes during nanofiltration processes of lactic acid solutions, $J_{v k}$ and deionised water through fouled membrane, $J_{w k}$ can be expressed by equations $1-4$ :

$J_{v k}=\frac{\Delta p}{R_{t}}$

$J_{w k}=\frac{\Delta p}{R_{m}+R_{i f}}$

where:

$R_{t}=R_{m}+R_{p f}$

$R_{p f}=R_{r f}+R_{i f}$

$R_{t}$ is the value of total membrane fouling, and $R_{p f}$ is the value of resistance caused by concentration polarization and fouling.

The active membrane layer resistance, $R_{m}$ was determined using experimental data obtained during nanofiltration of deionised water through clean membrane $\left(\mathrm{J}_{\mathrm{v}(\mathrm{dw})}\right.$ from Table 3) for investigated values of cross-flow velocity, $u$ and transmembrane pressure, $D p$ (Table 2). The active membrane layer resistance, $R_{m}$ obtained at the same transmembrane pressure conditions was lower at the higher cross-flow velocity, $\mathrm{u}=2.6 \mathrm{~m} / \mathrm{s}$ (Table 3 ).

The values of characteristic resistances calculated using equations 1-4 are summarized in Table 3.

The contribution of concentration polarization into mass transport resistances

The formation of boundary layer caused by the equilibrium between the back diffusion transport mechanism and the convective transport of solute during the initial time of pressure membrane processes is called a concentration polarization phenomena. The value of concentration polarization resistance due to the resistance-in-series model can be obtained from equation 5:

$J_{v(0)}=\frac{\Delta p}{R_{m}+R_{p}}$

where $\mathrm{Jv}_{(0)}$ is the value of permeate flux measured when the rejection of lactic acid achieved stability in the initial time of nanofiltration process at the level presented in Table 2.

The values used to characterize concentration polarization resistance are presented in Table 4.

\section{CONCLUSIONS}

Due to experimental research on pressure driven membrane processes the main reason of permeate flux reduction is an accumulation of concentration polarization and fouling effects. In this work values of fouling and concentration polarization resistance as well as the membrane active layer resistance in nanofiltration process of lactic acid solutions have been determined for chosen parameters presented in Table 2 with application of resistance-in-series model.

The performance of ZrIV/PAA dynamically formed nanofiltration membrane with varying process parameters in terms of extent of flux reduction was evaluated.

The impact of hydrodynamic conditions were evident to results providing NF of deionised water through clean membrane.

The analysis of deionised water filtration results showed that compilation of high velocity and transmembrane pressure causes increase of the permeate flux $\left(\mathrm{J}_{\mathrm{v}(\mathrm{dw})}\right.$ from Table 3).

The active membrane layer membrane resistance, $R_{m}$ strongly dependence on transmembrane pressure and cross-flow velocity, achieved the highest values for lowest value of cross- flow velocity (Table 3 ).

It was found that the major effect of mass transfer resistance is bound with properties of $\mathrm{Zr}(\mathrm{IV}) / \mathrm{PAA}$ membrane and operational parameters. Major effect on flux reduction and effectiveness of cleaning membrane has

Table 3. Experimental results of permeate fluxes and calculated values of fouling resistances for nanofiltration process of lactic acid solutions with $\mathrm{Zr}(\mathrm{IV}) / \mathrm{PAA}$ dynamically formed membranes

\begin{tabular}{|c|c|c|c|c|c|c|c|c|c|c|c|c|}
\hline Rejection of lactic acid & \multicolumn{3}{|c|}{$r=0.02$} & \multicolumn{3}{|c|}{$r=0.09$} & \multicolumn{3}{|c|}{$r=0.58$} & \multicolumn{3}{|c|}{$r=0.82$} \\
\hline Series number & 1 & 2 & 3 & 1 & 2 & 3 & 1 & 2 & 3 & 1 & 2 & 3 \\
\hline $\mathrm{t}, \mathrm{h}$ & 8.00 & 8.00 & 8.00 & 8.00 & 8.00 & 8.00 & 8.00 & 8.00 & 8.00 & 8.00 & 8.00 & 8.00 \\
\hline$J_{v(d w)} 10^{5}, \mathrm{~m}^{3} / \mathrm{m}^{2} \mathrm{~s}$ & 2.03 & 2.03 & 2.03 & 0.98 & 0.98 & 0.98 & 4.91 & 4.91 & 4.91 & 4.10 & 4.10 & 4.10 \\
\hline $\mathrm{J}_{\mathrm{vk}} 10^{5}, \mathrm{~m}^{3} / \mathrm{m}^{2} \mathrm{~s}$ & 1.24 & 1.21 & 1.19 & 0.21 & 0.20 & 0.19 & 1.03 & 0.86 & 0.80 & 0.72 & 0.67 & 0.65 \\
\hline $\mathrm{R}_{\mathrm{t}} 10^{-5}, \mathrm{MPam}^{2} \mathrm{~s} / \mathrm{m}^{3}$ & 1.13 & 1.16 & 1.18 & 6.67 & 7.00 & 7.37 & 5.34 & 6.40 & 6.88 & 7.64 & 8.20 & 8.45 \\
\hline $\mathrm{R}_{\mathrm{m}} 10^{-5}, \mathrm{MPam}^{2} \mathrm{~s} / \mathrm{m}^{3}$ & 0.69 & 0.69 & 0.69 & 1.43 & 1.43 & 1.43 & 1.12 & 1.12 & 1.12 & 1.34 & 1.34 & 1.34 \\
\hline $\mathrm{R}_{\mathrm{pf}} 10^{-5}, \mathrm{MPam}^{2} \mathrm{~s} / \mathrm{m}^{3}$ & 0.44 & 0.47 & 0.49 & 5.24 & 5.57 & 5.94 & 4.22 & 5.28 & 5.76 & 6.30 & 6.86 & 7.11 \\
\hline $\mathrm{J}_{\mathrm{wk}} 10^{5}, \mathrm{~m}^{3} / \mathrm{m}^{2} \mathrm{~s}$ & 1.81 & 1.44 & 1.61 & 0.22 & 0.21 & 0.20 & 1.15 & 0.94 & 0.86 & 0.86 & 0.75 & 0.71 \\
\hline $\mathrm{R}_{\mathrm{if}} 10^{-5}, \mathrm{MPam}^{2} \mathrm{~s} / \mathrm{m}^{3}$ & 0.08 & 0.28 & 0.18 & 4.92 & 5.24 & 5.57 & 3.66 & 4.74 & 5.28 & 5.06 & 5.99 & 6.40 \\
\hline $\mathrm{R}_{\mathrm{rf}} 10^{-5}, \mathrm{MPam}^{2} \mathrm{~s} / \mathrm{m}^{3}$ & 0.36 & 0.19 & 0.31 & 0.32 & 0.33 & 0.37 & 0.56 & 0.54 & 0.48 & 1.24 & 0.87 & 0.71 \\
\hline
\end{tabular}

Table 4. Experimental results of permeate fluxes and calculated values of concentration polarization resistances for nanofiltration process of lactic acid solutions with $\mathrm{Zr}(\mathrm{IV}) / \mathrm{PAA}$ dynamically formed membranes

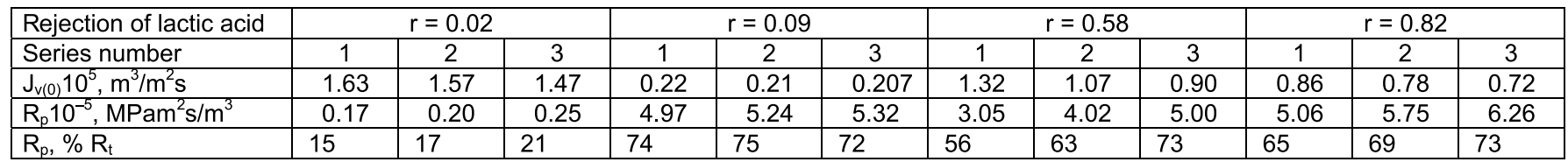


been observed for high concentration of lactic acid in feed solution $\mathrm{c}_{\mathrm{LA}}=1.0 \mathrm{~mol} / \mathrm{dm}^{3}$, transmembrane pressure, $\Delta \mathrm{p}=5.5 \mathrm{MPa}$ and $\mathrm{pH}=8.0$.

In spite of many advantages of ZrIV/PAA membranes application in practise more effective way of cleaning could be used (e.g. backflushing).

The operating parameters for analysis of concentration polarization and fouling phenomena evaluated earlier using statistical design method and concerns conditions enabling for obtained low (0.02-0.09) and high (0.58-0.82) values of lactic acid retention coefficients.

The research on effectiveness of (ZrIV/PAA) membrane lead to choice of the optimal process conditions even of flux reduction due to fouling and concentration polarization. resistances.

The $\mathrm{Zr}(\mathrm{IV}) / \mathrm{PAA}$ membrane may be successfully used in a nanofiltration process of lactic acid solutions if the operational parameters enabling for achievement of satisfactory values of retention coefficient and permeate flux have been properly selected. The selection of the latter values should give the best chance for membrane application in separation and concentration of lactic acid solutions.

\section{LITERATURE CITED}

1. Parajo, J.C., Alonso, J.L. \& Santos, V. (1996). Lactic acid from wood. Proc. Biochem. 31, 271-280. DOI: 10.1016/00329592(95)00059-3.

2. Turkson, A.K., Mikhlin, J.A. \& Weber, M.E. (1984). Dynamic membranes for ultrafiltration. J. Coll. Inter. Sci. 101, 583-586. DOI: 10.1016/0021-9797(84)90072-9.

3. Pessoa de Amorim, M.T. \& Ramos Afonso I.R. (2006). Control of irreversible fouling by application of dynamic membranes. Desalination. 192, 63-67. DOI: 10.1016/jdesal.2005.10.011.

4. Polom, E. \& Szaniawska, D. (2006). Rejection of lactic acid solutions by dynamically formed nanofiltration membranes using a statistical design method. Desalination 198, 208-214. DOI: 10.1016/j.desal.2006.04.002.

5. Polom, E. (2004). Research on nanofiltration process of lactic acid solutions. Unpublished doctoral dissertation, Technical University of Szczecin, Szczecin, Poland.

6. Gao, W., Liang, H., Ma, J., Han, M., Chen, Z., Han, Z. \& Li, G. (2011). Membrane fouling control in ultrafiltration technology for drinking water production: A review. Desalination 272, 1-8. DOI: 10.1016/j.desal.2011.01.051.

7. Shi X., Tal G., Hankins Nicolas P., Gitis V. (2014). Fouling and cleaning of ultrafiltration membranes: A review. J. Water Proc. Engine. 1, 121-138. DOI: 10.101/j.jwpe.2014.04.003.

8. Hoek, E. \& Elimelech, M. (2003). Cake - Enchanced Concentration Polarization: A New fouling mechanism for SaltRejecting Membranes. Environ. Sci. Technol. 37, 5581-5588. DOI: $10.1021 / \mathrm{es} 0262636$.

9. Konieczny, K. (2002). Modelling of membrane filtration of natural water for potable purposes. Desalination 143, 123-139. DOI: 10.1016/S0011-9164(02)00234-5.

10. Rajca, M., Bodzek, M. \& Konieczny, K. (2009), Application of mathematical models to the calculation of ultrafiltration flux in water treatment. Desalination 239, 100-110. DOI: 10.1016/j.desal.2008.03.010.

11. Konieczny K., Rajca M., Bodzek M., Kwiecińska A., (2009). Water treatment using hybrid method of coagulation and low-pressure membrane filtration. Environ. Prot. Eng. 35, 5-23. DOI: $10.5277 /$ epel40407.

12. Linares, R.V., Yangali-Quintanilla, V., Li, Z., Amy, G. (2011). Rejection of micropollutants by clean and fouled forward osmosis membrane. Water Res. 45, 6737-6744, DOI: 10.1016/j.waters.2011.10.37.

13. Polom, E. \& Szaniawska, D. (2003). Optimization of nanofiltration process of lactic acid solutions employing statistical experimental design. Environ. Prot. Eng. 29, 69-81, DOI: $10.5277 /$ epe.

14. Tanny, G.B. \& Johnson, J.S. (1978). The Structure of Hydrous $\mathrm{Zr}(\mathrm{IV})$ Oxide-Polyacrylate Membranes: Poly(acrylic Acid) Deposition. J. Appl. Polym. Sci. 22, 289-287. DOI: 10.1002/app.1978.070220121.

15. Ozari, Y., Tanny, G. \& Jagur-Grodziński, J. (1977) Dynamic Deposition of Polyacids on Porous Membrane Supports. J. Appl. Polym. Sci. 21, 555-572. DOI: 10.1002/ app.1977.070210221. 